\title{
Correlation between PD-L1 expression and MET gene amplification in patients with advanced non-small cell lung cancer and no other actionable oncogenic driver
}

\author{
Marta Domènech ${ }^{1,3}$, Ana M. Muñoz Marmol2 ${ }^{2}$ Jose Luis Mate ${ }^{2}$, Anna Estival ${ }^{1,3}$, \\ Teresa Moran ${ }^{1,3}$, Marc Cucurull ${ }^{1,3}$, Maria Saigi ${ }^{1,3}$, Ainhoa Hernandez ${ }^{1,3}$, Carolina \\ Sanz $^{2}$, Alba Hernandez-Gallego ${ }^{2}$, Aintzane Urbizu², Anna Martinez-Cardus ${ }^{3}$, Adrià \\ Bernat $^{3}$ and Enric Carcereny ${ }^{1,3}$ \\ ${ }^{1}$ Medical Oncology Department, Catalan Institute of Oncology Badalona, Germans Trias i Pujol Hospital, Badalona, Barcelona, \\ Spain \\ ${ }^{2}$ Pathology Department, Germans Trias i Pujol Hospital, Badalona, Barcelona, Spain \\ ${ }^{3}$ Badalona Applied Research Group in Oncology (BARGO), Institut d'Investigació en Ciències de la Salut Germans Trias i Pujol \\ (IGTP), Badalona, Barcelona, Spain
}

Correspondence to: Enric Carcereny, email: ecarcereny@iconcologia.net

Keywords: non-small cell lung cancer; oncogenic driver; PD-L1; MET amplification; smoking habit

Received: May 31, $2021 \quad$ Accepted: July 28, $2021 \quad$ Published: August 31, 2021

Copyright: ( 2021 Domènech et al. This is an open access article distributed under the terms of the Creative Commons Attribution License (CC BY 3.0), which permits unrestricted use, distribution, and reproduction in any medium, provided the original author and source are credited.

\section{ABSTRACT}

Non-small cell lung cancers (NSCLC) are the most common type of lung cancer and can be classified according to the presence of mutually exclusive oncogenic drivers. The majority of NSCLC patients present a non-actionable oncogenic driver, and treatment resistance through the amplification of the MET proto-oncogene (MET) or the expression of programmed cell death protein 1 ligand (PD-L1) is common. Herein, we investigated the relation between MET gene amplification and PD-L1 expression in patients with advanced NSCLC and no other actionable oncogenic driver (i.e., EGFR, $A L K, R O S 1)$. Our retrospective observational study analyzed data from 48 patients (78\% men, median age 66 years) admitted to the Germans Trias i Pujol Hospital, Spain, between July 2015 and February 2019. Patients presenting MET amplification showed a higher proportion of PD-L1 expression ( $93 \%$ vs. 39\%; $p<0.001)$ and overexpression (64\% vs. $27 \% ; p=0.020$ ) than those with non-amplified MET. PD-L1 expression was not significantly different when analyzed by sex $(p=0.624)$, smoking history $(p=0.429)$, and Eastern Cooperative Oncology Group Performance Status $(p=0.597)$ Overall survival rates were not significantly affected by MET amplification (high and intermediate amplification vs low amplification and non-amplificated $)(p=0.252)$ nor PD-L1 expression ( $>$ vs $=<50 \%)(p=0.893)$. In conclusion, a positive correlation was found between MET gene amplification and PD-L1 expression and highly expressed (above 50\%) in patients with NSCLC and no other actionable oncogenic driver. It could be translated as new guided-treatment oportunities for these patients.

\section{INTRODUCTION}

Cancer represents a heavy burden for society as a whole, with a high medical, economic, and psychosocial impact. Lung cancer is one of the most common cancers and has the highest death toll among them; $20 \%$ of all cancer-related deaths are attributed to lung cancer [1]. The vast majority of primary lung cancers are non-small cell lung cancer (NSCLC) [1]. NSCLCs can be classified at the molecular level according to the presence of oncogenic drivers that occur in genes crucial to tumor proliferation and survival. Several oncogenic drivers have been identified, which, in most cases, are mutually exclusive from one another [2]. However, only a fraction of them are 
druggable targets, also called actionable oncogenic drivers, for which targeted therapies are currently available. Among them, the most prevalent mutations in NSCLCs are seen in epidermal growth factor receptor $(E G F R)(10$ $15 \%$ ) followed by rearrangements in anaplastic lymphoma kinase $(A L K)(3-7 \%)$ and $R O S 1(1-2 \%)$ genes $[2,3]$. Nevertheless, most NSCLC patients present either a nonactionable oncogenic driver or an oncogenic alteration that has not yet been characterized $[4,5]$.

On the other hand, the emergence of treatment resistance is unavoidable [6]. In cases treated with EGFRtargeting tyrosine kinase inhibitors (TKI) (e.g., gefitinib, erlotinib), a common resistance mechanism occurs through the activation of the MET proto-oncogene (MET), also considered an oncogenic driver [6, 7]. In NSCLC, MET can either be activated through $M E T$ gene amplification, with a prevalence of $1-5 \%$, or exon 14 skipping mutations, occurring in around 3\% of NSCLCs [7]. The receptor tyrosine kinase encoded by MET is c-MET, whose ligand is the hepatocyte growth factor. Excessive c-MET activation in advanced cancers can cause tumor cell proliferation, motility, migration, and invasion [8]. Therapies with c-MET-TKIs (e.g., crizotinib, cabozantinib) have proven beneficial in lung cancer patients with $M E T$ gene amplification, preventing tumor growth, proliferation, and dissemination [9]. In addition, cancer cells can also achieve resistance through immune evasion. Programmed cell death protein 1 (PD-1) is expressed in T, B, and NK cells and, through the interaction with its ligand (PDL1), allows the cells expressing it to evade the immune response through different mechanisms, among which exhaustion, apoptosis, and anergy [10]. In several cancers, including lung cancer, this immune checkpoint can be hijacked by inducing PD-L1 expression on tumor cells, which avoids the response of the host's immune system $[11,12]$. Therefore, immunotherapy with anti-PD-1 (e.g., nivolumab, pembrolizumab) and anti-PD-L1 (e.g., atezolizumab, avelumab) agents has yielded positive results in patients with advanced NSCLC [13].

Several studies have proven that PD-L1 expression is correlated with wild-type $E G F R$ [12, 14, 15], ROS1 rearrangement [14], and erlotinib-resistant NSCLC [6], while it is not associated with $A L K$ mutations [16]. Besides, in some of these studies, $M E T$ gene amplification up-regulated PD-L1 expression, especially correlating with PD-L1 overexpression-considered as such for a tumor proportion score $>50 \%[6,15]$. However, to the best of our knowledge, no studies have been undertaken to explore the possible association of $M E T$ amplification and PD-L1 expression in advanced NSCLC patients presenting no other actionable oncogenic driver other than MET.

Therefore, the main aim of this study was to investigate the relation between $M E T$ gene amplification and PD-L1 expression in patients with advanced NSCLC and no other actionable oncogenic driver (i.e., $E G F R$, $A L K, R O S 1)$. We also analyzed the difference in PD-
L1 expression according to sex, Eastern Cooperative Oncology Group Performance Status (PS), and smoking history of our studied population. Finally, we aimed to establish the effect of PD-L1 expression and MET gene amplification on the survival rates of our cohort.

\section{RESULTS}

The baseline characteristics of our cohort are summarized in Table 1. Of the 50 patients eligible for our study, 39 (78\%) were men, $43(86 \%)$ were or had been smokers, and $74 \%$ had a PS of 0 or 1 . The median age was 66 years (range: 44-82). Regarding histology, 38 (76\%) patients presented an adenocarcinoma, $4(8 \%)$ a squamous cell carcinoma, and on $8(16 \%)$ the histology was not performed. In our cohort, $15(30 \%)$ patients showed an intermediate or high $M E T / C E P 7$ ratio, i.e., amplified MET. Positive PD-L1 expression was found in 27 (54\%) patients, among which 19 (38\%) showed high-over $50 \%$ - expression levels, i.e., PD-L1overexpression. In 2 (4\%) patients PD-L1 was not possible to determine; hence, our analyses were performed on a total of 48 patients.

A higher proportion of positive PD-L1 expression was found among patients with amplified MET (93\%) than among those with non-amplified MET $(41 \%, p<$ 0.001) (Figure 1). Likewise, the proportion of patients overexpressing PD-L1 above 50\% was higher among those with amplified $M E T$ (64\%) than among those with non-amplified $M E T(27 \%, p=0.020)$. However, most patients did not overexpress PD-L1 $(n=29,62 \%)$ (Figure 2).

PD-L1 expression was not significantly different when analyzed by sex $(p=0.624)$, smoking history $(p=0.429)$, and PS $(p=0.597)$ (Table 2$)$. However, the number of patients not overexpressing PD-L1 was invariably higher than those overexpressing it by sex, smoking history, and PS categories. Only in the subgroup of patients who had never smoked this trend was reversed, with a higher number of patients overexpressing PD-L1.

The median follow-up duration was 30 months and the median overall survival (OS) of our cohort was 16.3 months (95\% confidence interval [CI]: 2.3-30.4) (Figure 3). The difference in OS of patients with amplified MET (median: 38.2 months, 95\% CI: 5.7-70.5) was not statistically significant from those with non-amplified MET (median: 7.8 months, 95\% CI: 3.6-12.0; $p=0.252$ ) (Figure 4). Likewise, no statistically significant difference in OS was found between patients overexpressing PD-L1 (median: 38.0 months, 95\% CI: 0-93.8) and those not overexpressing it (median: 5.2 months, 95\% CI: 0.7-9.6; $p$-value $=0.184)($ Figure 5$)$.

\section{DISCUSSION}

To the best of our knowledge, this was the first study to show a positive correlation between $M E T$ gene 


\begin{tabular}{lc}
\hline Sex & $\begin{array}{c}\text { Overall } \\
(\boldsymbol{n}=\mathbf{5 0})\end{array}$ \\
$\quad$ Male & $39(78)$ \\
$\quad$ Female & $11(22)$ \\
Age (years), median (range) & $66(44-82)$ \\
Smoking history & \\
$\quad$ Current & $15(30)$ \\
Former & $28(56)$ \\
Never & $5(10)$ \\
Not specified & $2(4)$ \\
Histology & \\
Adenocarcinoma & $38(76)$ \\
Squamous-cell carcinoma & $4(8)$ \\
Not specified & $8(16)$ \\
ECOG performance status & \\
$0-1$ & $37(74)$ \\
$2-3$ & $13(26)$ \\
PD-L1 expression & \\
Negative & $21(42)$ \\
$1-50 \%$ & $8(16)$ \\
$>$ 50\% & $19(38)$ \\
Not determined & $2(4)$ \\
MET gene amplification & \\
Non-amplified & $35(70)$ \\
Amplified & $15(30)$ \\
\hline
\end{tabular}

ECOG: Eastern Cooperative Oncology Group. Figures are absolute numbers (and \%) unless otherwise stated.

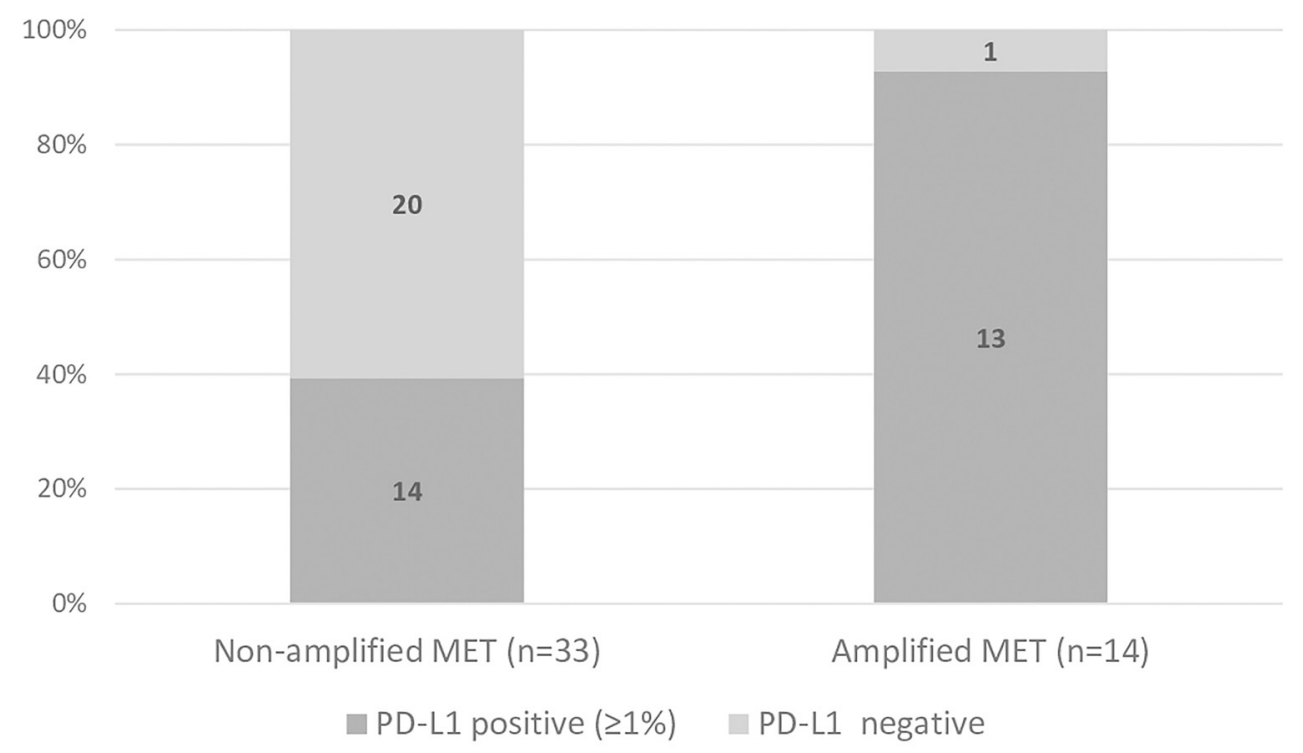

Figure 1: Proportion of patients presenting positive ( $\geq 1 \%)$ and negative PD-L1 in non-amplified and amplified $M E T$ groups. (Chi square test: $p<0.001$ ). 
Table 2: PD-L1 expression stratified by sex, ECOG performance status, and smoking history

\begin{tabular}{lcccc}
\hline & PD-L1 $\leq \mathbf{5 0} \%$ & PD-L1 $\mathbf{5 0 \%}$ & Overall $(\boldsymbol{n}=\mathbf{4 8})$ & $\boldsymbol{p}$-value \\
\hline Sex & & & & 0.624 \\
$\quad$ Male & $23(61)$ & $15(39)$ & $38(100)$ & \\
$\quad$ Female & $6(60)$ & $4(40)$ & $10(100)$ & 0.429 \\
Smoking history & & & & \\
$\quad$ Current & $8(53)$ & $7(47)$ & $15(100)$ & \\
$\quad$ Former & $17(61)$ & $9(39)$ & $28(100)$ & \\
$\quad$ Never & $2(40)$ & $3(60)$ & $5(100)$ & 0.597 \\
$\quad$ Not specified & $2(100)$ & $0(0)$ & $2(4)$ & \\
ECOG performance status & & & & \\
$0-1$ & $21(60)$ & $14(40)$ & $25(100)$ & $13(100)$ \\
$2-3$ & $8(62)$ & $5(38)$ &
\end{tabular}

ECOG: Eastern Cooperative Oncology Group. Figures represent absolute numbers (and \%).

amplification and PD-L1 expression in patients with NSCLC and no other actionable oncogenic driver (i.e., $E G F R, A L K, R O S 1)$. Indeed, although the absolute numbers were the same, the proportion of patients expressing and overexpressing PD-L1 was higher among those with amplified $M E T$.

The baseline characteristics of our NSCLC cohort showed, as expected, a predominance of the male sex, current or former smokers, and adenocarcinoma. The ratios found in our study for positive PD-L1 expression (52\%) and overexpression $(36 \%)$ were in agreement with those reported previously on 791 NSCLC patients (63\% of PDL1 positive and $30 \%$ of overexpression) [17]. Likewise, a retrospective study on 389 NSCLC samples found $42 \%$ of positive PD-L1 expression and 19\% of overexpression, also similar to our results [15]. Peculiarly, in our cohort, the number of patients showing positive PD-L1 expression or overexpression was the same in MET amplified and non-amplified groups, but these proportions were invariably higher in those exhibiting $M E T$ amplification. The correlation between MET amplification and PD-L1 expression has been previously studied in NSCLCs with other actionable oncogenic drivers, especially $E G F R$ mutation. The retrospective study abovementioned found that PD-L1 expression was correlated with MET amplification in proportions close to ours [15]. Also, in a small study performed on NSCLC patients with an EGFRmutation, $M E T$ gene amplification was significantly associated with PD-L1 expression [18]. Besides, this correlation was demonstrated in an in vitro study with cells resistant to erlotinib [6]. Finally, our results are in agreement with those from a previous study that showed a higher occurrence of PD-L1 expression in MET amplified patients and demonstrated a positive correlation between $M E T$ amplification and PD-L1 expression [19].

Globally, more than $80 \%$ of lung cancers in men and almost $60 \%$ in women are caused by tobacco smoking [20]. Therefore, a correlation between smoking and PD-L1

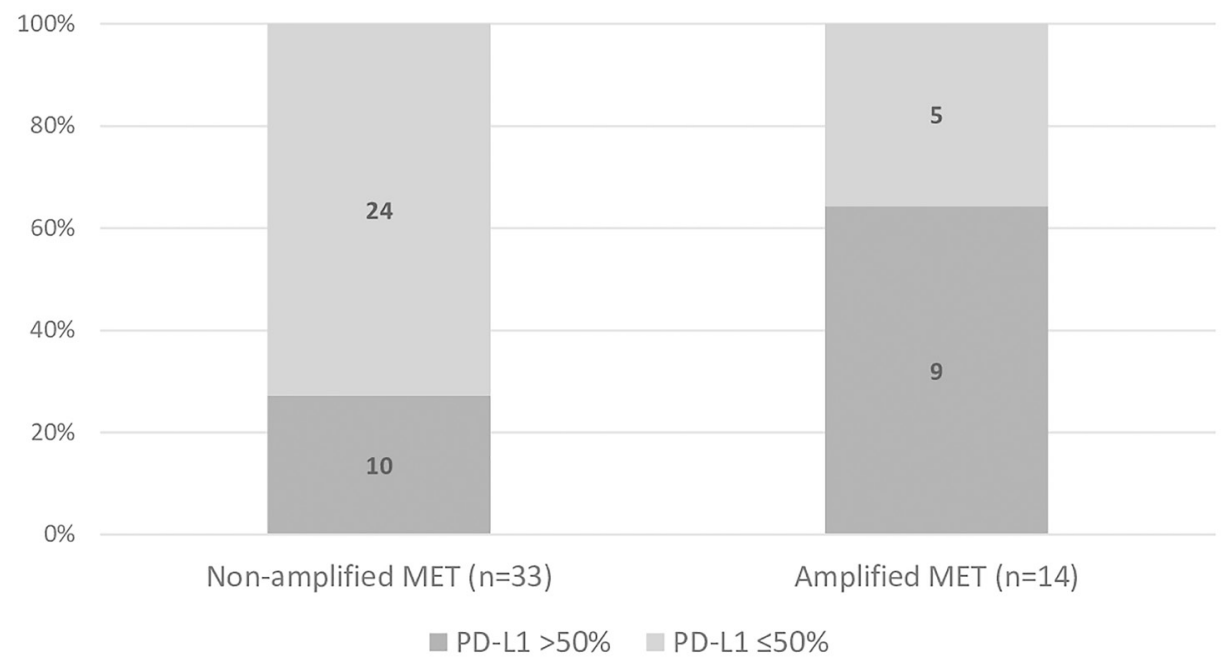

Figure 2: Proportion of patients overexpressing ( $>50 \%)$ or not overexpressing $(\leq 50 \%)$ PD-L1 in in non-amplified and amplified MET groups. (Chi square test: $p=0.020$ ). 
expression is expected and has been repeatedly reported [21-23]. However, in our study, no correlation was found between PD-L1 expression and sex, smoking history, or PS. Interestingly, these results are in agreement with a large prospective study where none of these parameters had a significant impact on PD-L1 expression level [17] and with a previous meta-analysis in which only tumor differentiation showed a correlation with PD-L1 expression [10]. This could be explained, in our case, by the small size of our sample and the univariate analysis of data.

The OS of our cohort was in line with those reported for NSCLC patients with no actionable oncogenic driver

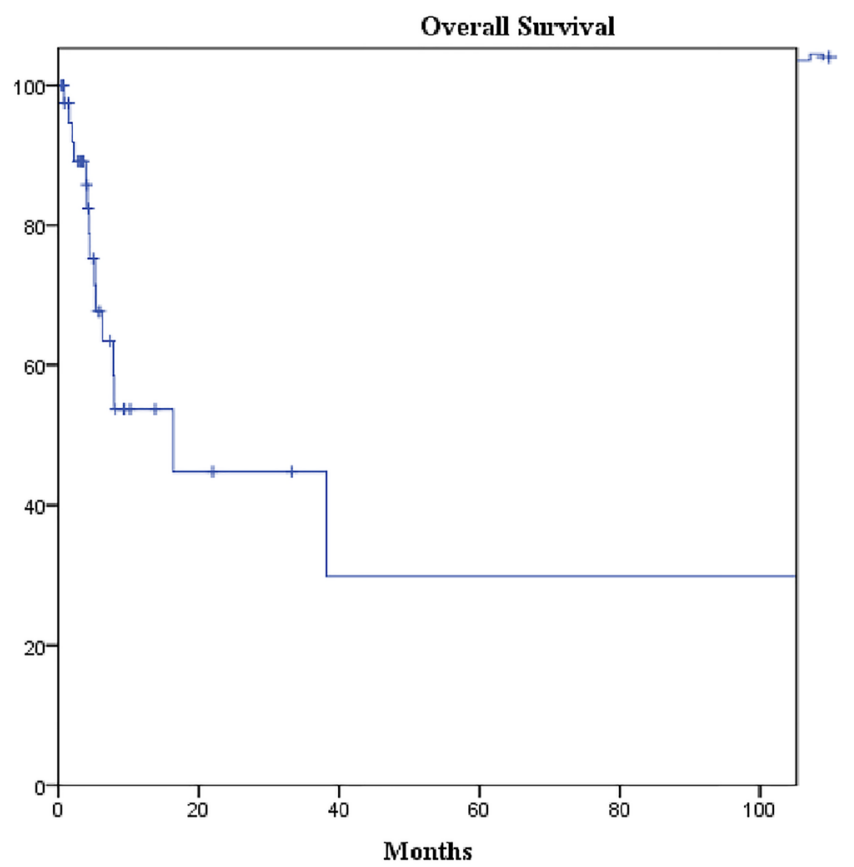

Figure 3: Kaplan-Meier curve of overall survival of the cohort. Median overall survival: 16.3 months (95\% CI: 2.3-30.4).

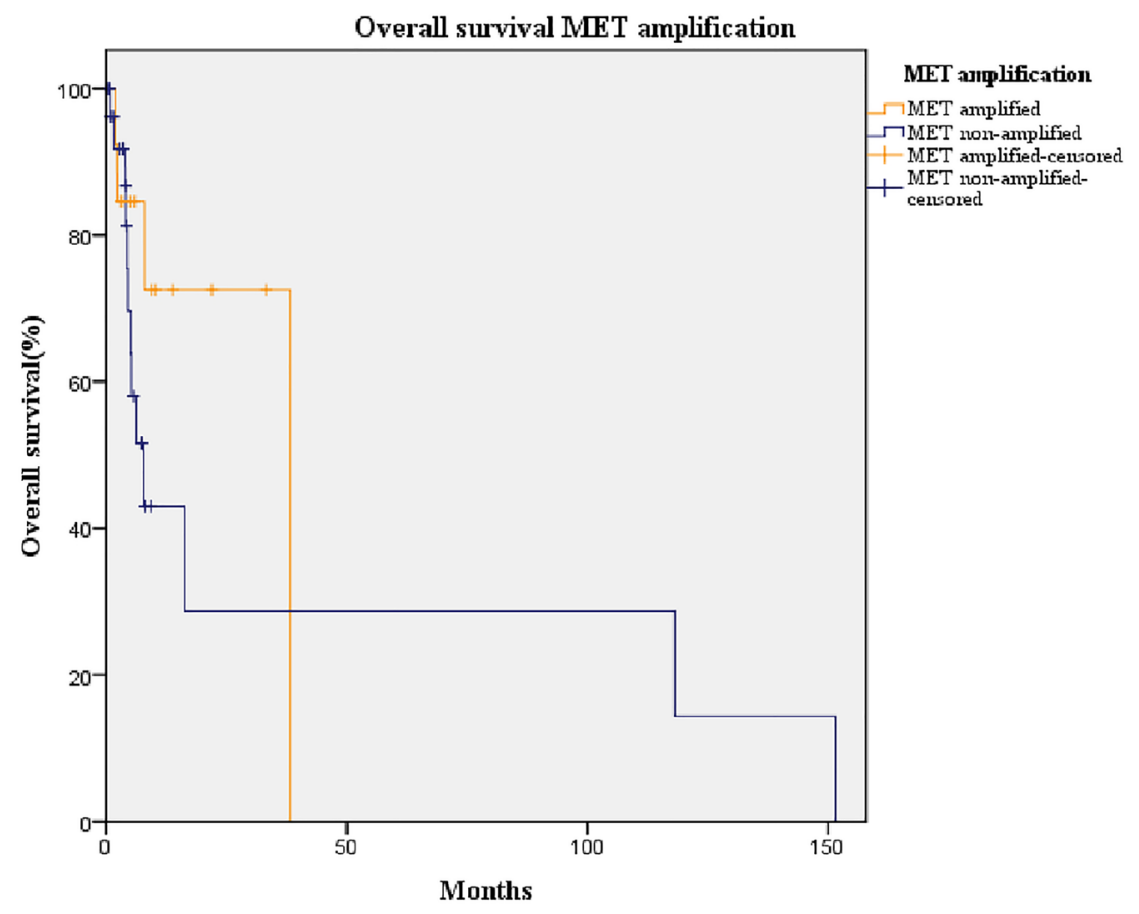

Figure 4: Kaplan-Meier curve of overall survival of patients with amplified $M E T$ (orange line) and non-amplified MET (blue line). Median overall survival of non-amplified MET group: 7.0 months (95\% CI: 3.6-12.0). Median overall survival of amplified MET group: 38.0 months (95\% CI: $5.7-70.5 ; p=0.202)$. 
[24]. However, MET amplification showed no statistically significant impact in OS, in contrast with previous studies [25-27]. This may be due to differences in the cut-off values used to define $M E T$ positivity or amplification, which lack consensus, and in the number of patients with stage IV tumors; in those patients, $M E T$ amplification did not further impact the OS [26]. However, in our study, the median OS of amplified (7.0 months) and non-amplified MET (38.0 months) groups displayed a non-negligible difference, but the small size of our sample precluded statistical confirmation of this result. Although PD-L1 has been found to be a poor prognosis factor $[10,16]$, we found that PD-L1 expression was not correlated with OS, as previously reported [28-30]. This could be explained, again, by the influence of the patients' tumor stages and their ethnicity; no influence of PD-L1 expression has been reported on the OS of patients with stage IV tumors and was only an indicator of poor prognosis in Asian populations but not in non-Asians [16].

The main strength of our study was the homogeneity of the sample, which allowed, for the first time, to study the correlation between PD-L1 expression and MET gene amplification in patients with advanced NSCLC and no other actionable oncogenic driver. However, we were limited by the small sample size available and the inherent constraints of a retrospective study. In addition, the absence of a general consensus on cut-off values for MET amplification compelled us to use arbitrary ones. Therefore, we urge the community to arrive at this most needed consensus and to undertake prospective and large studies to validate or refute the results here described.

In conclusion, a positive correlation was found between $M E T$ gene amplification and PD-L1 expression and overexpression in patients with NSCLC and no other actionable oncogenic driver. In our study, PD-L1 expression was not affected by sex, PS, or smoking history, and PD-L1 expression and MET gene amplification did not affect the OS rates of our cohort. Further studies are needed to appraise the impact this finding may have on possible treatments for these patients.

\section{MATERIALS AND METHODS}

\section{Study design}

This was a retrospective observational study carried with data recorded in the Spanish Thoracic Tumor Registry (TTR), a National Registry of lung cancer cases managed and sponsored by the Spanish Lung Cancer Group (SLCG) (Grupo Español de Cáncer de Pulmón). The SLCG is an independent cooperative group formed mostly by oncologists and counting more than 500 members. In 2015, the SLCG decided to start a nationwide multicenter epidemiological study aimed at ascertaining the characteristics of lung cancer cases, their treatments, and survival, in an effort to offset the existing lack of information caused by the absence of a cancer registry with national coverage. Current regional registries barely cover

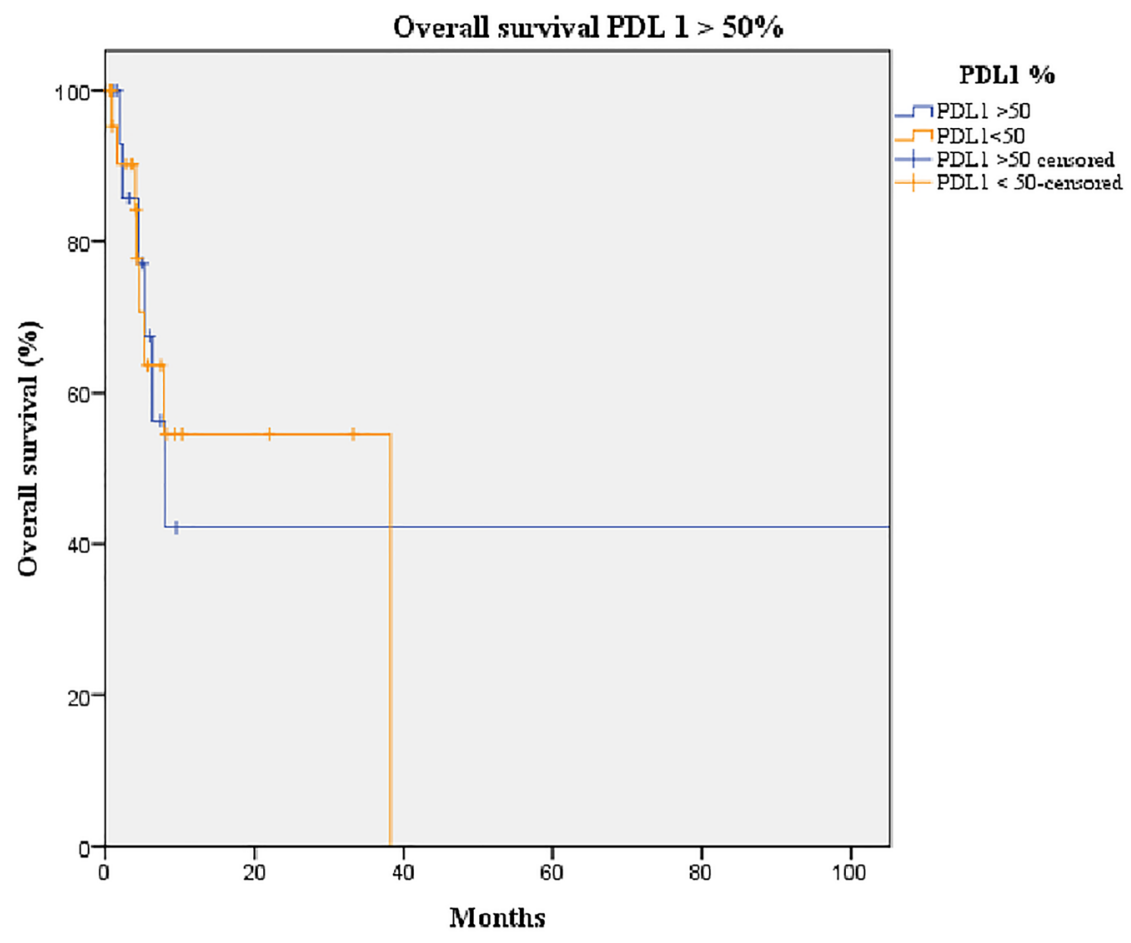

Figure 5: Kaplan-Meier curve of overall survival of patients overexpressing PD-L1 (orange line) and not overexpressing PD-L1 (blue line). Median overall survival of the group overexpressing PD-L1 (> 50\%): 8 months (95\% CI: 4.0-11.9). Median overall survival of the group not overexpressing PD-L1 $(\leq 50 \%)$ : 38 months (95\% CI: $0-N R ; p$-value $=0.893$ ). 
$30 \%$ of the Spanish population and only exist in some particular regions. The TTR was opened to all Spanish hospitals and the first patient was enrolled in August 2016. The recruitment is still ongoing with more than 75 hospitals taking part. The methodology group of the SLCG designed specifically an electronic questionnaire to be used by the TTR. The information from all participants was entered through an electronic questionnaire by clinicians. The questionnaire had different sections: 1) demographic data (gender, age, etc.); 2) detailed history of tobacco use; 3) lung cancer characteristics at diagnosis (including a full list of possible symptoms); 4) all treatments received (with detailed information on each); 5) presence of specific mutations in driver genes at diagnosis; 6) disease progression; and 7) survival data.

\section{Patients}

This study used data from patients admitted to the Catalan Institute of Oncology Badalona Germans Trias i Pujol Hospital between July 2015 and February 2019. We collected data recorded in the Spanish TTR from patients of our center. We included data from patients with advanced NSCLC and whose MET expression had been analyzed and showed no other mutation on relevant genes (i.e., EGFR, ALK, ROS1).

The TTR has been approved by the Clinical Research Ethics Committee of Puerta de Hierro University Hospital.

\section{Genotyping}

We evaluated MET amplification by fluorescence in situ hybridization (FISH) using the Zyto Light ${ }^{\circledR}$ SPEC MET/CEN 7 Dual Color Probe. Briefly, we deparaffinized 4- $\mu \mathrm{m}$-thick paraffin-embedded tissue sections and processed them with the Histology FISH Accessory Kit (Dako). After pretreatment and enzymatic digestion according to the manufacturer's instructions, we codenatured slides for $4 \mathrm{~min}$ at $85^{\circ} \mathrm{C}$ and hybridized them overnight at $37^{\circ} \mathrm{C}$ on a Hybridizer (Dako). Following hybridization, we removed coverslips and washed slides at $65^{\circ} \mathrm{C}$ for $2 \mathrm{~min}$ in $2 \mathrm{X} \mathrm{SSC} / 0.3 \%$ Tween-20. After dehydration in a graded ethanol series, we counterstained samples with fluorescence mounting medium containing 4',6-diamidino-2-phenylindole (DAPI). Finally, we scored hybridization signals in at least 20 non-overlapping nuclei.

No consensus exists on the most appropriate diagnostic cut-off point for $M E T$ amplification. Several approaches based either on gene copy number, the ratio of $M E T$ to chromosome enumerating probe against chromosome 7 (CEP7), or a combination thereof have been proposed [31]. In our study, we applied the criteria of Noonan et al. [32], who categorized samples in four groups conforming to $M E T / C E P 7$ ratios: not positive $(<1.8)$, low $(\geq 1.8$ to $\leq 2.2)$, intermediate $(>2.2$ to $<5)$ and high amplified ( $\geq 5$ ). Accordingly, we classified our samples with $M E T / C E P 7$ ratio $\leq 2.2$ (not positive or low) as non-amplified MET and those with $M E T / C E P 7$ ratio > 2.2 (intermediate or high) as amplified $M E T$.

\section{Immunohistochemistry}

We processed tissue slides in a BenchMark ULTRA platform instrument (Ventana Medical Systems, Roche, Tucson, AZ, USA) and stained them with SP263 antibody, which we prediluted according to the manufacturer's instructions. Following the established recommendations, we quantified the percentage of cells with membrane positivity (partial or complete expression) for each tumor. We did not assess tumor necrosis areas and discarded cases in which at least 50 viable cells were not available [33]. We determined the tumor proportion score by calculating the percentage of tumor cells membrane staining at any intensity. We considered PD-L1 expression in tumor cells positive if $\geq 1 \%$ of tumor cells had membranous staining of any intensity and high if $>50 \%$.

\section{Statistical analysis}

We described categorical variables as absolute frequencies and percentages and continuous variables as median and ranges. We compared categorical variables using the chi-square test. We calculated OS from the date of diagnosis to the date of last follow-up or death. We conducted survival analysis with the Kaplan-Meier method and we compared differences among groups and subgroups with the log-rank test. We set the statistical significance level at $p<0.05$.

\section{Author contributions}

The authors declare that the research was conducted in the absence of any commercial or financial relationships that could be construed as a potential conflicts of interest.

\section{ACKNOWLEDGMENTS}

EC handled the conceptualization and methodology; MD handled analysis; The others handled the validation.

\section{CONFLICTS OF INTEREST}

Authors have no conflicts of interest to declare.

\section{REFERENCES}

1. Brahmer JR, Govindan R, Anders RA, Antonia SJ, Sagorsky S, Davies MJ, Dubinett SM, Ferris A, Gandhi L, Garon EB, Hellmann MD, Hirsch FR, Malik S, et al. The Society for Immunotherapy of Cancer consensus statement on 
immunotherapy for the treatment of non-small cell lung cancer (NSCLC). J Immunother Cancer. 2018; 6:75. https:// doi.org/10.1186/s40425-018-0382-2. [PubMed]

2. Cardarella S, Johnson BE. The impact of genomic changes on treatment of lung cancer. Am J Respir Crit Care Med. 2013; 188:770-75. https://doi.org/10.1164/rccm.2013050843PP. [PubMed]

3. Mayekar MK, Bivona TG. Current Landscape of Targeted Therapy in Lung Cancer. Clin Pharmacol Ther. 2017; 102:757-64. https://doi.org/10.1002/cpt.810. [PubMed]

4. Herbst RS, Morgensztern D, Boshoff C. The biology and management of non-small cell lung cancer. Nature. 2018; 553:446-54. https://doi.org/10.1038/nature25183. [PubMed]

5. McCoach CE, Doebele RC. The minority report: targeting the rare oncogenes in NSCLC. Curr Treat Options Oncol. 2014; 15:644-57. https://doi.org/10.1007/s11864-014-03108. [PubMed]

6. Demuth C, Andersen MN, Jakobsen KR, Madsen AT, Sørensen BS. Increased PD-L1 expression in erlotinibresistant NSCLC cells with MET gene amplification is reversed upon MET-TKI treatment. Oncotarget. 2017; 8:68221-29. https://doi.org/10.18632/oncotarget.19920. [PubMed]

7. Halliday PR, Blakely CM, Bivona TG. Emerging Targeted Therapies for the Treatment of Non-small Cell Lung Cancer. Curr Oncol Rep. 2019; 21:21. https://doi.org/10.1007/ s11912-019-0770-x. [PubMed]

8. Kawakami H, Okamoto I, Okamoto W, Tanizaki J, Nakagawa K, Nishio K. Targeting MET Amplification as a New Oncogenic Driver. Cancers (Basel). 2014; 6:1540-52. https://doi.org/10.3390/cancers6031540. [PubMed]

9. Martin V, Chiriaco C, Modica C, Acquadro A, Cortese M, Galimi F, Perera T, Gammaitoni L, Aglietta M, Comoglio PM, Vigna E, Sangiolo D. Met inhibition revokes IFN $\gamma$ induction of PD-1 ligands in MET-amplified tumours. Br J Cancer. 2019; 120:527-36. https://doi.org/10.1038/s41416018-0315-3. [PubMed]

10. Wang A, Wang HY, Liu Y, Zhao MC, Zhang HJ, Lu ZY, Fang YC, Chen XF, Liu GT. The prognostic value of PD-L1 expression for non-small cell lung cancer patients: a metaanalysis. Eur J Surg Oncol. 2015; 41:450-56. https://doi. org/10.1016/j.ejso.2015.01.020. [PubMed]

11. D'Incecco A, Andreozzi M, Ludovini V, Rossi E, Capodanno A, Landi L, Tibaldi C, Minuti G, Salvini J, Coppi E, Chella A, Fontanini G, Filice ME, et al. PD-1 and PD-L1 expression in molecularly selected non-smallcell lung cancer patients. Br J Cancer. 2015; 112:95-102. https://doi.org/10.1038/bjc.2014.555. [PubMed]

12. Ji M, Liu Y, Li Q, Li X, Ning Z, Zhao W, Shi H, Jiang J, Wu C. PD-1/PD-L1 expression in non-small-cell lung cancer and its correlation with EGFR/KRAS mutations. Cancer Biol Ther. 2016; 17:407-13. https://doi.org/10.1080/15384 047.2016.1156256. [ [PubMed]
13. Abdel-Rahman O. Correlation between PD-L1 expression and outcome of NSCLC patients treated with antiPD-1/PD-L1 agents: A meta-analysis. Crit Rev Oncol Hematol. 2016; 101:75-85. https://doi.org/10.1016/j. critrevonc.2016.03.007. [PubMed]

14. Lee J, Park CK, Yoon HK, Sa YJ, Woo IS, Kim HR, Kim SY, Kim TJ. PD-L1 expression in ROS1-rearranged non-small cell lung cancer: A study using simultaneous genotypic screening of EGFR, ALK, and ROS1. Thorac Cancer. 2019; 10:103-10. https://doi.org/10.1111/17597714.12917. [PubMed]

15. Albitar M, Sudarsanam S, Ma W, Jiang S, Chen W, Funari V, Blocker F, Agersborg S. Correlation of MET gene amplification and TP53 mutation with PD-L1 expression in non-small cell lung cancer. Oncotarget. 2018; 9:13682-93. https://doi.org/10.18632/oncotarget.24455. [PubMed]

16. Zhang M, Li G, Wang Y, Wang Y, Zhao S, Haihong $\mathrm{P}$, Zhao H, Wang Y. PD-L1 expression in lung cancer and its correlation with driver mutations: a meta-analysis. Sci Rep. 2017; 7:10255. https://doi.org/10.1038/s41598-017-109257. [PubMed]

17. Skov BG, Rørvig SB, Jensen THL, Skov T. The prevalence of programmed death ligand-1 (PD-L1) expression in non-small cell lung cancer in an unselected, consecutive population. Mod Pathol. 2020; 33:109-17. https://doi. org/10.1038/s41379-019-0339-0. [PubMed]

18. Han JJ, Kim DW, Koh J, Keam B, Kim TM, Jeon YK, Lee $\mathrm{SH}$, Chung DH, Heo DS. Change in PD-L1 Expression After Acquiring Resistance to Gefitinib in EGFR-Mutant NonSmall-Cell Lung Cancer. Clin Lung Cancer. 2016; 17:26370.e2. https://doi.org/10.1016/j.cllc.2015.11.006. [PubMed]

19. Saigi M, Alburquerque-Bejar JJ, Mc Leer-Florin A, Pereira C, Pros E, Romero OA, Baixeras N, EsteveCodina A, Nadal E, Brambilla E, Sanchez-Cespedes M. MET-Oncogenic and JAK2-Inactivating Alterations Are Independent Factors That Affect Regulation of PDL1 Expression in Lung Cancer. Clin Cancer Res. 2018; 24:4579-87. https://doi.org/10.1158/1078-0432.CCR-180267. [PubMed]

20. Whiteman DC, Wilson LF. The fractions of cancer attributable to modifiable factors: A global review. Cancer Epidemiol. 2016; 44:203-21. https://doi.org/10.1016/j. canep.2016.06.013. [PubMed]

21. Tseng JS, Yang TY, Wu CY, Ku WH, Chen KC, Hsu KH, Huang YH, Su KY, Yu SL, Chang GC. Characteristics and Predictive Value of PD-L1 Status in Real-World Non-Small Cell Lung Cancer Patients. J Immunother. 2018; 41:292-99. https://doi.org/10.1097/CJ.0000000000000226. [PubMed]

22. Norum J, Nieder C. Tobacco smoking and cessation and PD-L1 inhibitors in non-small cell lung cancer (NSCLC): a review of the literature. ESMO Open. 2018; 3:e00406. https://doi.org/10.1136/esmoopen-2018-000406. [PubMed]

23. Ng TL, Liu Y, Dimou A, Patil T, Aisner DL, Dong Z, Jiang T, Su C, Wu C, Ren S, Zhou C, Camidge DR. Predictive 
value of oncogenic driver subtype, programmed death-1 ligand (PD-L1) score, and smoking status on the efficacy of PD-1/PD-L1 inhibitors in patients with oncogene-driven non-small cell lung cancer. Cancer. 2019; 125:1038-49. https://doi.org/10.1002/cncr.31871. [PubMed]

24. Kim SY, Halmos B. Choosing the best first-line therapy: NSCLC with no actionable oncogenic driver. Lung Cancer Manag. 2020; 9:LMT36. https://doi.org/10.2217/lmt-20200003. [PubMed]

25. Dimou A, Non L, Chae YK, Tester WJ, Syrigos KN. MET gene copy number predicts worse overall survival in patients with non-small cell lung cancer (NSCLC); a systematic review and meta-analysis. PLoS One. 2014; 9:e107677. https://doi.org/10.1371/journal.pone.0107677. [PubMed]

26. Fang L, Chen H, Tang Z, Kalhor N, Liu CH, Yao H, Hu S, Lin P, Zhao J, Luthra R, Singh RR, Routbort MJ, Hong $\mathrm{D}$, et al. MET amplification assessed using optimized FISH reporting criteria predicts early distant metastasis in patients with non-small cell lung cancer. Oncotarget. 2018; 9:12959-70. https://doi.org/10.18632/oncotarget.24430. [PubMed]

27. Awad MM, Leonardi GC, Kravets S, Dahlberg SE, Drilon A, Noonan SA, Camidge DR, Ou SI, Costa DB, Gadgeel SM, Steuer CE, Forde PM, Zhu VW, et al. Impact of MET inhibitors on survival among patients with non-small cell lung cancer harboring MET exon 14 mutations: a retrospective analysis. Lung Cancer. 2019; 133:96-102. https://doi.org/10.1016/j.lungcan.2019.05.011. [PubMed]

28. Hellwig K, Schimrigk S, Beste C, Muller T, Gold R. Increase in relapse rate during assisted reproduction technique in patients with multiple sclerosis. Eur Neurol. 2009; 61:65-68. https://doi.org/10.1159/000177937. [PubMed]
29. Cooper WA, Tran T, Vilain RE, Madore J, Selinger CI, Kohonen-Corish M, Yip P, Yu B, O'Toole SA, McCaughan BC, Yearley JH, Horvath LG, Kao S, et al. PD-L1 expression is a favorable prognostic factor in early stage non-small cell carcinoma. Lung Cancer. 2015; 89:181-88. https://doi.org/10.1016/j.lungcan.2015.05.007. [PubMed]

30. Sorensen SF, Zhou W, Dolled-Filhart M, Georgsen JB, Wang Z, Emancipator K, Wu D, Busch-Sørensen M, Meldgaard P, Hager H. PD-L1 Expression and Survival among Patients with Advanced Non-Small Cell Lung Cancer Treated with Chemotherapy. Transl Oncol. 2016; 9:64-69. https://doi.org/10.1016/j.tranon.2016.01.003. [PubMed]

31. Guo R, Luo J, Chang J, Rekhtman N, Arcila M, Drilon A. MET-dependent solid tumours - molecular diagnosis and targeted therapy. Nat Rev Clin Oncol. 2020; 17:569-87. https://doi.org/10.1038/s41571-020-0377-z. [PubMed]

32. Noonan SA, Berry L, Lu X, Gao D, Barón AE, Chesnut P, Sheren J, Aisner DL, Merrick D, Doebele RC, VarellaGarcia M, Camidge DR. Identifying the Appropriate FISH Criteria for Defining MET Copy Number-Driven Lung Adenocarcinoma through Oncogene Overlap Analysis. J Thorac Oncol. 2016; 11:1293-304. https://doi. org/10.1016/j.jtho.2016.04.033. [PubMed]

33. Büttner R, Gosney JR, Skov BG, Adam J, Motoi N, Bloom KJ, Dietel M, Longshore JW, López-Ríos F, PenaultLlorca F, Viale G, Wotherspoon AC, Kerr KM, Tsao MS. Programmed Death-Ligand 1 Immunohistochemistry Testing: A Review of Analytical Assays and Clinical Implementation in Non-Small-Cell Lung Cancer. J Clin Oncol. 2017; 35:3867-76. https://doi.org/10.1200/ JCO.2017.74.7642. [ubMed] 